\title{
Estudo farmacobotânico de duas espécies de Anileira (Indigofera suffruticosa e Indigofera truxillensis, Leguminosae) com propriedades farmacológicas
}

\author{
Giselle Monte Cassiano Canavaci Barros, Simone de Pádua Teixeira* \\ Departamento de Ciências Farmacêuticas, Faculdade de Ciências Farmacêuticas de Ribeirão Preto, \\ Universidade de São Paulo, Av. do Café, s/n, 14040-903 Ribeirão Preto-SP, Brasil
}

\begin{abstract}
RESUMO: Indigofera suffruticosa e Indigofera truxillensis são espécies de Leguminosae que se destacam no gênero por suas propriedades farmacológicas. O objetivo deste trabalho foi estabelecer um controle de qualidade morfológico para as matérias-primas vegetais obtidas destas duas espécies, por meio de análises da superfície e organoléptica do pó foliolar e estudos anatômicos e histoquímicos dos folíolos, do caule e da raiz. A análise dos pós mostrou que a forma e ornamentação dos tricomas tectores são bons caracteres diagnósticos da matériaprima pulverizada com partículas maiores que $53 \mu \mathrm{M}$, e que o odor em I. suffruticosa é forte e desagradável, com sabor fracamente amargo não persistente e em I. truxillensis é fraco e agradável e de sabor muito amargo e persistente. As espécies apresentaram estrutura anatômica de folíolos, entrenós caulinares e raízes laterais muito semelhantes; exceto pela epiderme papilosa em ambas as faces foliolares em I. truxillensis e apenas na face adaxial em I. suffruticosa. Compostos fenólicos foram detectados nos folíolos e alcalóides foram detectados nos caules e nas raízes (em maior quantidade nestas) de ambas as espécies. A presença de alcalóides nas raízes de $I$. suffruticosa e I. truxillensis é semelhante à observada em espécies de leguminosas ictiotóxicas incluídas no "complexo timbó", cujas raízes são tóxicas devido à presença de rotenóides.
\end{abstract}

Unitermos: Indigofera, anatomia, controle de qualidade, histoquímica, folha, caule, raiz.

\begin{abstract}
Pharmacobotanical studies of wild indigo species (Indigofera suffruticosa and Indigofera truxillensis, Leguminosae, with pharmacological properties". The Leguminosae genus Indigofera has two important pharmacological species, Indigofera suffruticosa and I. truxillensis. The present work aims to establish a morphological quality control for vegetal drugs obtained from these two species through the analyses of surface and organoleptic features in leaflet powder, and also through anatomical and histochemical studies in leaflet, shoot and root. Powder analyses evidenced that shape and ornamentation of the simple trichomes are good diagnostic characters for the sprayed drug, with particles bigger than $53 \mu \mathrm{m}$; moreover, odor was strong and awkward, with non-persistent, weakly bitter taste in I. suffruticosa, and weak and pleasant, with more persistent, bitter taste in I. truxillensis. Similar anatomical structures were found in leaflets, cauline internodes and lateral roots in both species, except for papillose epidermic cells that occurred in both leaflet sides in I. truxillensis, and only on the adaxial side in I. suffruticosa. Phenolic compounds were found in leaflets, and alkaloids in shoots and roots (greater amount) of both studied species. The occurrence of alkaloids in roots of I. suffruticosa and I. truxillensis seems to be similar to that observed in ichthyotoxic legume species that belong to the so-called "timbó complex", whose roots are toxic due to rotenoids.
\end{abstract}

Keywords: Indigofera, anatomy, quality control, histochemistry, leaf, shoot, root.

\section{INTRODUÇÃO}

O gênero pantropical Indigofera L. (Leguminosae, Papilionoideae, Indigofereae) é constituído por cerca de 700 espécies, representadas por plantas herbáceas e arbustivas. Dentre as várias espécies de Indigofera, destacam-se I. suffruticosa Mill. e I. truxillensis Kunth. por sua distribuição ampla e propriedades medicinais. Representantes de $I$. suffruticosa e de I. truxillensis apresentam porte arbustivo ou subarbustivo, ereto e ramificado, atingindo até 2,5 $m$ de altura (Moreira \& Tozzi 1997), caracterizados por folhas com folíolos numerosos, inflorescências menores que as folhas e frutos numerosos desde a base do eixo da inflorescência (Bortoluzzi et al., 2003). I. truxillensis pode ser distinguida de I. suffruticosa por apresentar frutos retos e folíolos com tricomas malpiguiáceos nas duas faces (Moreira \& Tozzi, 1997). I. suffruticosa é a espécie mais amplamente distribuída, ocorrendo em quase todo o território brasileiro (Moreira \& Tozzi 1997) 
e em outros países da América, desde o sul dos Estados Unidos até a Argentina, sendo aclimatada na Ásia, Africa e Austrália (White, 1980). I. truxillensis ocorre nos Estados de Minas Gerais (Bentham, 1859), Mato Grosso do Sul e São Paulo (Moreira \& Tozzi 1997), além de ser encontrada em outros países da América, como Peru (Bentham, 1859) e desde o México até a Bolívia (Burkart, 1942).

Os órgãos vegetativos de I. suffruticosa apresentam valor medicinal (Vieira, 1992; Martins et al., 2000), como antiespasmódico, sedativo, estomáquico, emenagôgo e antídoto contra o mercúrio e o arsênio (Martins et al., 2000). Sua raiz é empregada ainda como febrífuga, diurética, purgativa e insetífuga (Vieira, 1992). Os órgãos vegetativos de 1 . truxillensis também possuem propriedades medicinais, sendo muito utilizados pela população (Martins et al., 2000). Ambas espécies apresentam importância na agropecuária (Tokarnia et al., 2000) e na farmacologia (Bhalla \& Dakwake, 1978; Williams, 1981; Rao et al., 1984; Garcez et al., 1989; Vieira, 1992).

Apesar de seu emprego como medicinais, estas espécies apresentam toxicidade para animais. As partes aéreas e as sementes de I. suffruticosa foram consideradas tóxicas em experimentos com bovinos, resultando em anemia hemolítica nos mesmos, além, de outras patologias encontradas no fígado e rim por intoxicação pelo consumo da planta (Barbosa Neto et al., 2001). Ribeiro et al. (1991) encontraram efeitos hepatotóxicos após o consumo de pequena quantidade de extrato aquoso do fruto de I. suffruticosa por ratos, além de efeitos citotóxicos após o consumo de quantidades maiores. As partes vegetativas de I. truxillensis também foram consideradas tóxicas em experimentos com bovinos, resultando em taquicardia, anorexia e edema pulmonar (Tokarnia et al., 2000). A ingestão de folhas e frutos de I. truxillensis resultou em alterações histopatológicas em ovinos (Carvalho et al., 1990). Estudos fitoquímicos destas espécies detectaram a presença de substâncias tóxicas como o nitropropanoil-glicopiranosideo (Garcez et al., 1989), e o alcalóide denominado indospicina (Tokarnia et al., 2000), sem, contudo, relacionarem as substâncias encontradas às partes da planta que ocasionaram distúrbios aos animais.

Indigofera suffruticosa já é bastante utilizada pela população por suas propriedades medicinais (Bhaskr et al., 1982; Leite et al., 2003; Agra et al., 2007) e, portanto, começa a despertar o interesse de pesquisadores da fitoterapia. O desenvolvimento de fitoterápicos é controlado a partir de uma identificação segura do material vegetal utilizado. AAgência Nacional de Vigilância Sanitária, por meio da resolução RDC 17, de $24 /$ fevereiro/2000, estabeleceu que a solicitação do registro de um produto fitoterápico só ocorre mediante a identificação oficial da planta que compõe a matéria prima do produto, bem como de um laudo de análise macro e microscópica do órgão vegetal utilizado, emitido por profissional habilitado (Anvisa, 2000). Desta forma, o controle de qualidade para espécies vegetais medicinais é de extrema importância (Bonati, 1973; Marques et al., 2007; Ferrante et al., 2007).

$\mathrm{O}$ objetivo deste trabalho foi estabelecer um controle de qualidade para as drogas vegetais provenientes de I. suffruticosa e I. truxillensis por meio da análise do pó foliolar e da anatomia e histoquímica dos folíolos, do caule e da raiz, pois segundo Bhalla \& Dakwake (1978), Williams (1981), Rao et al. (1984), Garcez et al. (1989) e Vieira (1992), estas são as partes vegetais que apresentam interesse farmacológico nestas espécies.

\section{MATERIAL E MÉTODOS}

Foram realizados exames de superfície e organoléptico do pó foliolar e estudos anatômicos e histoquímicos de folíolos completamente expandidos (região da nervura central e mesofilo), entrenós caulinares (região do 3 ontrenó) e raízes secundárias. Os materiais foram coletados de pelo menos dois indivíduos de cada espécie, cultivadas na Faculdade de Ciências Farmacêuticas de Ribeirão Preto-USP, Ribeirão Preto, SP. O material testemunho encontra-se no herbário da Faculdade de Filosofia, Ciências e Letras de Ribeirão Preto (SPFR) sob os números 07923 e 07924 para $I$. suffruticosa e 07922 para I. truxillensis.

A análise do pó foi realizada a partir da coleta e seleção manual de $3,15 \mathrm{~g}$ e $5,48 \mathrm{~g}$ de folíolos frescos de I. suffruticosa e I. truxillensis, respectivamente. Os materiais foram estabilizados em estufa de ar circulante à temperatura de $40{ }^{\circ} \mathrm{C}$, seguido de trituração manual e passagem em um sistema composto por três tamises com malhas de 200, 270 e 325 meshes, os quais representam respectivamente $75 \mu \mathrm{M}, 53 \mu \mathrm{M}$ e $45 \mu \mathrm{M}$ (Brito, 2004).

Para o exame em microscopia eletrônica de varredura, o pó foliolar foi dividido em frascos segundo os tamanhos obtidos dos tamises para cada espécie, montado em suportes metálicos, colado sobre fita adesiva de Carbono, coberto com Ouro em um metalizador Balzers SCD 050 e analisado em um Microscópio Eletrônico de Varredura JEOL JSM 5200 em $10 \mathrm{kv}$. As fotomicrografias foram obtidas em uma câmera Sinar 67.

Os testes histoquímicos foram realizados em materiais fixados em solução de Karnovsky em tampão fosfato $0,075 \mathrm{M}(\mathrm{pH} 7,2-7,4)$ por $24 \mathrm{~h}$ (Karnovsky, 1965), lavados em tampão fosfato $0,075 \mathrm{M}(\mathrm{pH} 7,2-7,4)$, desidratados em série álcool-xilólica, incluídos em parafina e seccionados (8 a $14 \mu \mathrm{M}$ de espessura) em micrótomo rotativo. Os cortes foram submetidos à reação com Azul brilhante de Comassie para proteínas (Fisher, 1968), Sudan Black B para substâncias lipofílicas (Jensen, 1962), Reagente de Wagner para alcalóides (Furr \& Mahlberg, 1981), Cloreto férrico para compostos fenólicos (Johansen, 1940), Reagente 
de PAS para polissacarídeos (O’Brien \& McCully, 1981), e montados em resina sintética para a confecção de lâminas permanentes. As fotomicrografias foram obtidas em fotomicroscópio Leica DM 4500 e as escalas obtidas nas mesmas condições ópticas.

\section{RESULTADOS}

\section{Análise do pó foliolar}

O pó de I. suffruticosa é fino, de cor verde-escuro, cheiro forte e desagradável, com sabor fracamente amargo não persistente. I. truxillensis apresenta pó fino, de cor verde-escuro, cheiro fraco e agradável e de sabor muito amargo e persistente.

A análise em MEV das partículas dos folíolos pulverizados, correspondentes a 75 e $53 \mu \mathrm{M}$, em ambas as espécies, mostra tricomas tectores bifurcados, inseridos na epiderme pelo centro, retos, inteiros, ornamentados, além de depósitos de cera em flocos (Figuras 1-4). Já nas partículas com $45 \mu \mathrm{M}$, foram observados flocos de cera e poucos tricomas tectores, em sua maioria, quebrados (Figuras 5 e 6 ).

\section{Anatomia}

Alâmina foliolar de ambas as espécies é constituída por epiderme unisseriada com células retangulares, mesofilo dorsiventral com parênquima paravenal e feixes vasculares colaterais. I. truxillensis distingue-se de I. suffruticosa por apresentar células epidérmicas papilosas em ambas as superfícies foliolares (Figuras 8 e 17). A nervura central (Figuras 7 e 16) é constituída por três a quatro camadas de colênquima e pelo feixe vascular colateral. Na periferia do tecido floemático, em I. suffruticosa, foram observadas células grandes, com paredes pecto-celulósicas (Figura 7).

O caule utilizado como droga vegetal encontra-se em início de estrutura secundária em ambas as espécies. Apresenta, da região externa para a interna, epiderme unisseriada, revestida por fina cutícula; quatro a cinco camadas de células colenquimáticas subepidérmicas; várias camadas de células parenquimáticas contendo cloroplastos; endoderme unisseriada contendo substâncias fenólicas; cilindro vascular constituído por uma camada pericíclica, elementos floemáticos, elementos xilemáticos e medula parenquimática (Figuras 9, 10, 18 e 19). Cristais prismáticos ocorrem na região do floema. A faixa cambial é observada nos feixes vasculares e na região interfascicular.

As raízes laterais de ambas as espécies, utilizadas como droga vegetal, encontram-se em estrutura secundária. Apresentam periderme constituída por três camadas de súber, felogênio e feloderme unisseriados; duas a três camadas de células parenquimáticas, provavelmente restantes do córtex (Figura 14); cilindro vascular com elementos floemáticos externos

aos xilemáticos, sendo o periciclo parenquimático e unisseriado. Os raios parenquimáticos do xilema e floema secundários apresentam 2-3 séries; células parenquimáticas e fibras são observadas acompanhando os vasos agrupados, raramente isolados (Figuras 11-13, 22 e 23). Fibras derivadas dos elementos do floema primário são observadas na região externa ao floema secundário.

\section{Histoquímica}

O folíolo de ambas as espécies apresenta grãos protéicos e compostos fenólicos nas células dos parênquimas paliçádico e lacunoso (Figuras 7, 8, 16 e 17), sendo que o teste para proteínas apresenta-se fortemente positivo em I. suffruticosa. Em I. truxillensis, os compostos fenólicos também ocorrem no parênquima paravenal (Figura 17). Grãos de amido são encontrados em pequena quantidade nos parênquimas paliçádico e lacunoso. Substâncias lipofílicas e alcalóides estão ausentes (Tabela 1).

O caule de ambas as espécies apresenta grãos protéicos nas células da medula e do periciclo (Figuras 10 e 18). O resultado para compostos fenólicos mostrase fortemente positivo para as células da endoderme (Figuras 9 e 19) e para algumas células da medula. Em I. truxillensis também ocorrem compostos fenólicos nos elementos de vasos do sistema vascular (Figura 20). Alcalóides são encontrados na endoderme em pequenas quantidades, associados aos compostos fenólicos. A parede das células do floema e do córtex, em ambas as espécies, é PAS-positiva. Em I. truxillensis, polissacarídeos são observados nas células do xilema (Figura 21). Substâncias lipofílicas não são observadas (Tabela 1).

Nas raízes, grãos protéicos ocorrem nas células do parênquima radial e vasicêntrico (Figura 11) e do súber em ambas as espécies; em I. suffruticosa também são observados nas células do córtex. Os alcalóides ocorrem em grande quantidade nas células do parênquima radial e vasicêntrico (Figuras 12 e 22), dos elementos restantes do floema primário e do córtex em ambas as espécies. Grãos de amido ocorrem nas células dos parênquimas radial e vasicêntrico (Figuras 13 e 23) e do córtex. Gotas de óleo são evidenciadas em grande quantidade nas células do súber das duas espécies (Figuras 14 e 24) e do parênquima vasicêntrico em I. suffruticosa (Figura 15). Compostos fenólicos são ausentes (Tabela 1).

\section{DISCUSSÃO}

A análise morfológica dos pós foliolares de I. suffruticosa e I. truxillensis mostrou que a forma e ornamentação dos tricomas tectores constituem bons caracteres para a diagnose da matéria-prima pulverizada "anileira", desde que as partículas não sejam menores que $53 \mu \mathrm{M}$. Cabe ressaltar que os tricomas de $I$. 

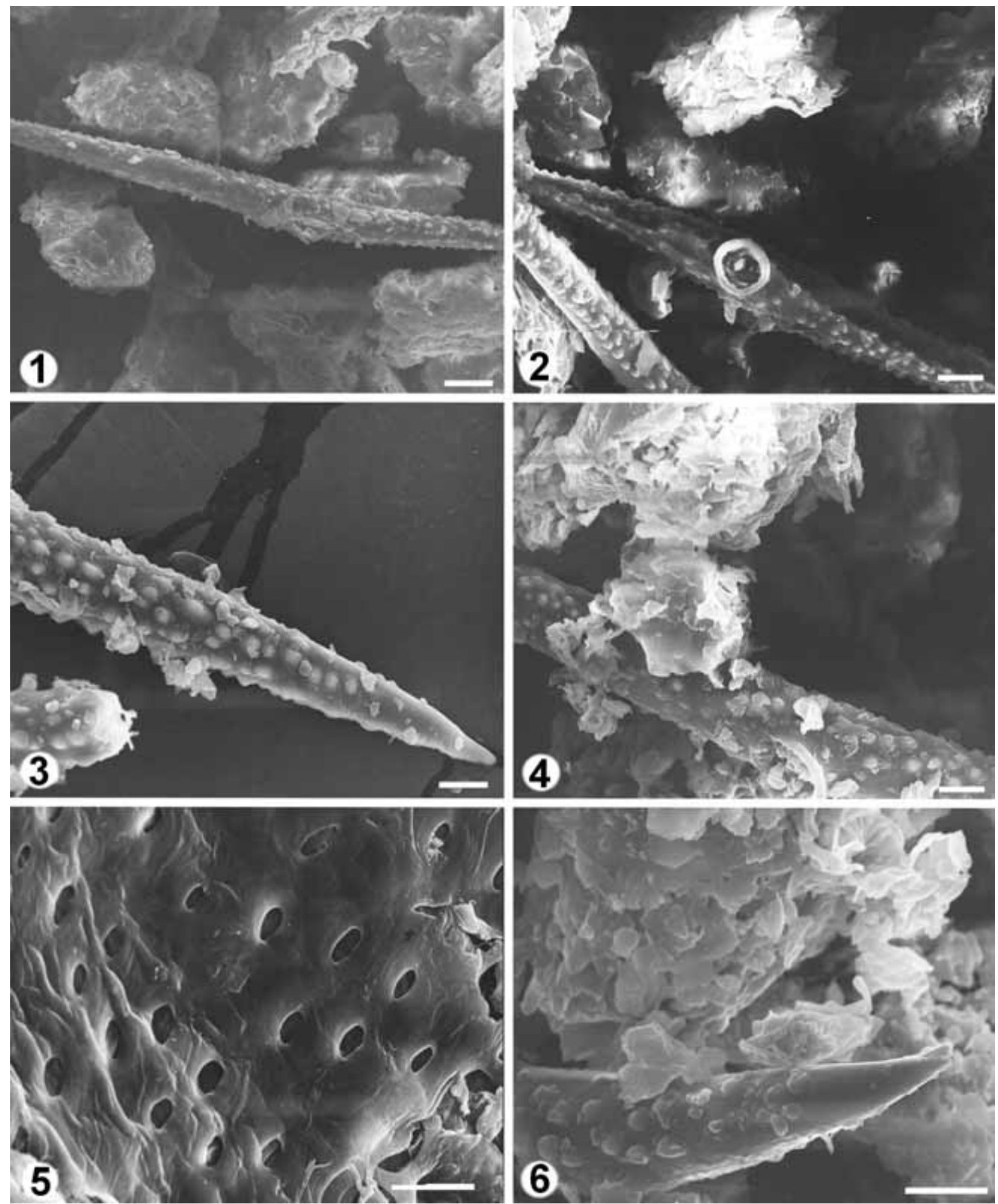

Figuras 1-6. Eletromicrografias (MEV) dos folíolos pulverizados de Indigofera suffruticosa e I. truxillensis. 1. Partículas de I. suffruticosa com $75 \mu \mathrm{M}$. 2. Partículas de I. suffruticosa com $53 \mu \mathrm{M}$. 3. Partículas de I. truxillensis com $75 \mu \mathrm{M}$. 4. Partículas de I. truxillensis com $53 \mu \mathrm{M}$. 5. Partículas de I. suffruticosa com $45 \mu \mathrm{M}$. 6. Partículas de I. truxillensis com $45 \mu \mathrm{M}$. Escalas $=10$ $\mu \mathrm{M}$. 

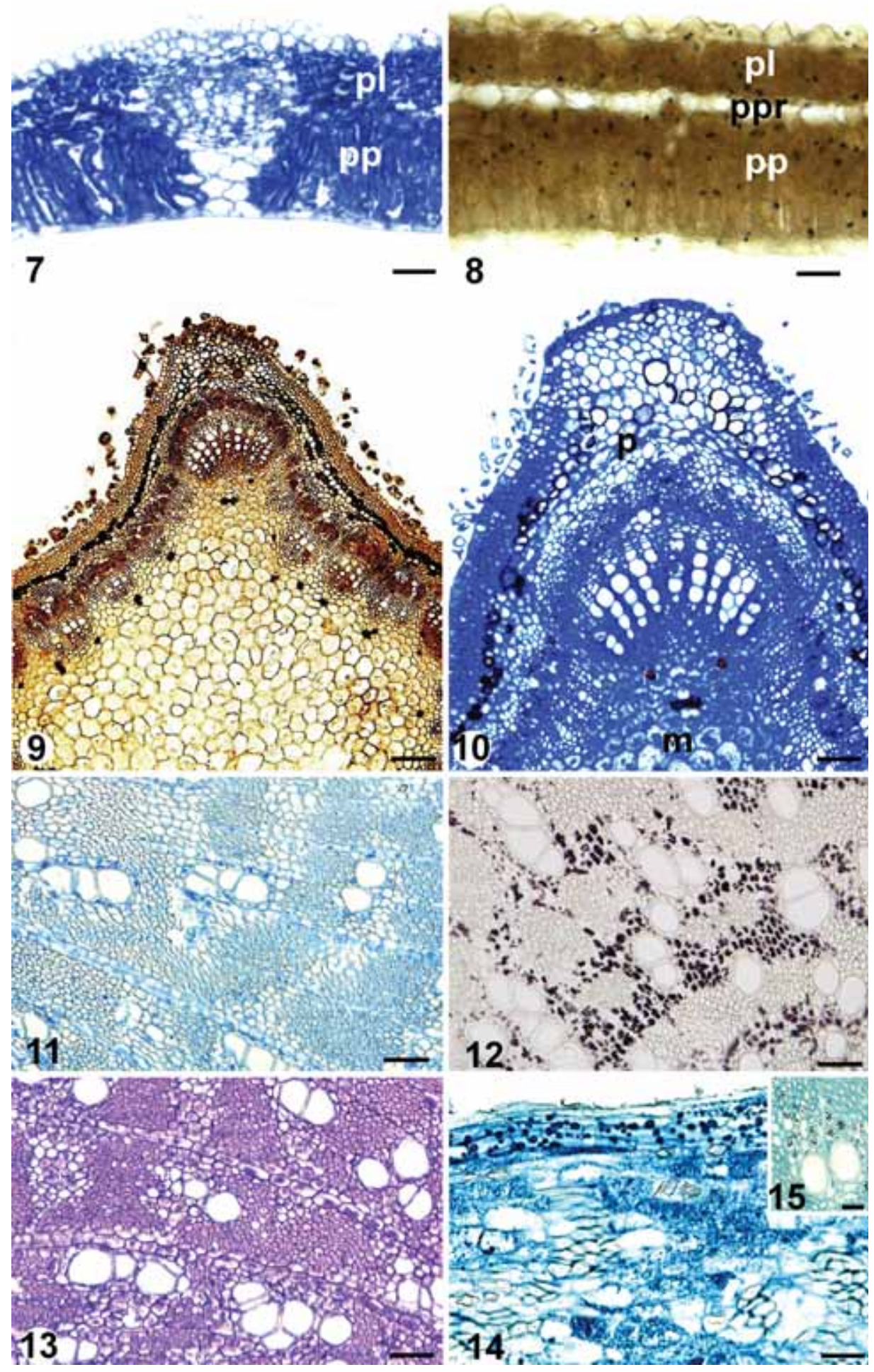

Figuras 7-15. Fotomicrografias de cortes transversais do folíolo, do caule e da raiz de I. suffruticosa. 7. Folíolo, no qual se observa a presença de substâncias protéicas (em azul) nas células dos parênquimas paliçádico e lacunoso. 8. Folíolo, mostrando compostos fenólicos (em negro) nas células dos parênquimas paliçádico e lacunoso. 9. Caule, mostrando compostos fenólicos (em negro) nas células da endoderme e da medula. 10. Caule, evidenciando substâncias protéicas (em azul) nas células da medula e do periciclo (*). 11. Raiz, evidenciando substâncias protéicas (em azul) nas células dos parênquimas radial e vasicêntrico. 12. Raiz, mostrando alcalóides (em marrom) nas células dos parênquimas radial e vasicêntrico. 13. Raiz, mostrando grãos de amido (em rosa) nas células dos parênquimas radial e vasicêntrico. 14. Raiz, mostrando gotas de óleo (em azul) nas células do súber e cristais prismáticos. 15. Raiz, mostrando gotas de óleo (em azul) nas células do parênquima vasicêntrico. pl - parênquima lacunoso; pp - parênquima paliçádico; ppr - parênquima paravenal; m - medula; p - periciclo. Escalas: figs. 7, 8,14 = 30 $\mu \mathrm{M}$; fig. $9=100 \mu \mathrm{M}$; figs $10-13=50 \mu \mathrm{M}$; fig. $15=25 \mu \mathrm{M}$. 

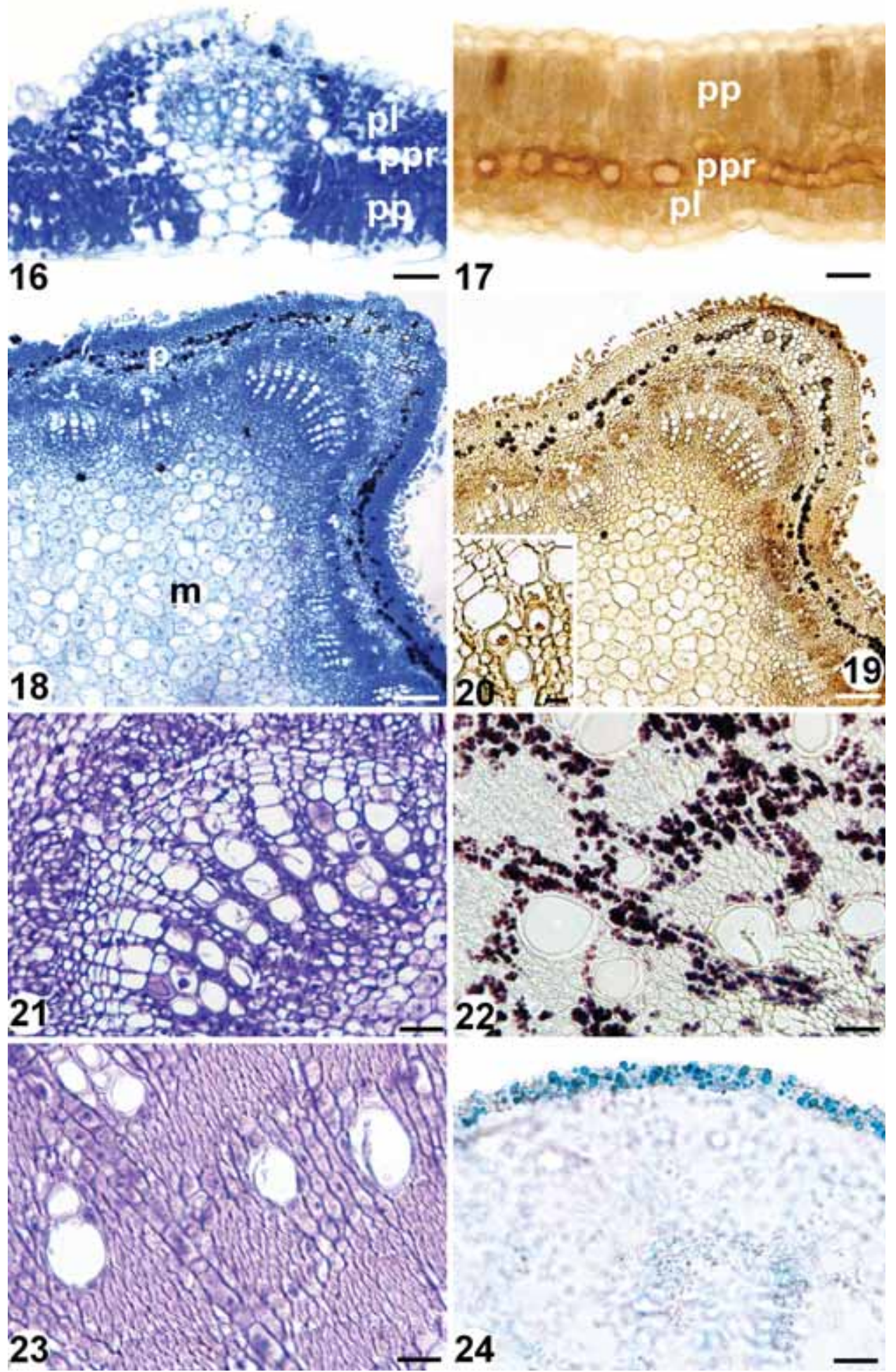

Figuras 16-24. Fotomicrografias de cortes transversais do folíolo, do caule e da raiz de I. truxillensis. 16. Folíolo, mostrando grãos protéicos (em azul) nas células dos parênquimas paliçádico e lacunoso. 17. Folíolo, mostrando compostos fenólicos (em negro) em algumas células dos parênquimas paliçádico, lacunoso e paravenal. 18. Caule, evidenciando substâncias protéicas (em azul) nas células da medula e do periciclo. 19. Caule, mostrando compostos fenólicos (em negro) nas células da endoderme e da medula. 20. Caule, mostrando compostos fenólicos nas células do sistema vascular. 21. Caule, mostrando grãos de amido (em rosa) nas células do sistema vascular $(*)$. 22. Raiz com células dos parênquimas radial e vasicêntrico contendo alcalóides (marrom). 23. Raiz, mostrando células dos parênquimas radial e vasicêntrico PAS-positivas. 24. Raiz, mostrando gotas de óleo (em azul) nas células do súber. pl - parênquima lacunoso; pp - parênquima paliçádico; ppr - parênquima paravenal; $\mathrm{m}$ - medula. Escalas: figs. 16, 17, 21-24=30 $\mu \mathrm{M}$; fig. $20=15 \mu \mathrm{M}$; figs. $18,19=100 \mu \mathrm{M}$. 
Tabela 1. Testes histoquímicos realizados nos folíolos, nos entrenós caulinares e nas raízes laterais de Indigofera suffruticosa e $I$. truxillensis. Símbolos: + indica fracamente positivo; ++, positivo; +++, fortemente positivo e -, negativo.

\begin{tabular}{lcccccc}
\hline \multirow{2}{*}{ Substâncias } & \multicolumn{3}{c}{ I. suffruticosa } & \multicolumn{3}{c}{ I. truxillensis } \\
\cline { 2 - 7 } & Folha & Caule & Raiz & Folha & Caule & Raiz \\
\hline Proteínas & +++ & ++ & + & ++ & ++ & ++ \\
Lipídios & - & - & +++ & - & - & +++ \\
Alcalóides & - & + & +++ & - & + & +++ \\
Compostos Fenólicos & ++ & +++ & - & ++ & +++ & - \\
Polissacarídeos & + & + & ++ & + & ++ & ++ \\
\hline
\end{tabular}

suffruticosa são levemente curvos se comparados aos de I. truxillensis (comparar Figura 1 a 3). Tricomas tectores bifurcados são característicos do gênero Indigofera, utilizados inclusive em chaves taxonômicas por Moreira \& Tozzi (1997). A análise organoléptica também permitiu separar o pó das duas espécies: o odor em I. suffruticosa é forte e desagradável, com sabor fracamente amargo, não persistente, e em I. truxillensis é fraco e agradável e de sabor muito amargo e persistente. Visto que a maioria das espécies de Indigofera é considerada tóxica (Kissmann \& Groth, 1999), a diagnose correta das partes utilizadas como medicinais em I. suffruticosa pode evitar problemas de intoxicação na população e em animais.

A irritação química provocada em bovinos pela ingestão de caule e folhas de I. suffruticosa (Barbosa Neto et al., 2001) e de I. truxillensis (Tokarnia et al., 2000) pode estar relacionada à presença de compostos fenólicos e proteínas, pois idioblastos cristalíferos e alcalóides foram observados em pequena quantidade nestes órgãos aqui estudados. Espécies tóxicas, para as quais têm sido relatados acidentes por ingestão da planta por crianças e animais domésticos (Oliveira et al., 2003), apresentam grande quantidade de ráfides e drusas, além de alcalóides presentes no látex da folha e do caule, como em Dieffenbackia picta (Araceae) (Ferreira et al., 2006). Em relação às proteínas, representantes da família Leguminosae são bastante conhecidos pela presença de proteínas tóxicas. Os gêneros Abrus e Phaseolus, por exemplo, possuem abrina, fasina e robina, proteínas responsáveis por causarem efeitos citotóxicos (Kissmann \& Groth, 1999). Entretanto, estes mesmos compostos fenólicos e proteínas, em doses e forma de utilização corretas, podem apresentar propriedades medicinais em I. suffruticosa (Lorenzi \& Abreu-Matos, 2002).

A raiz de I. suffruticosa e I. truxillensis, apesar de não ter sido relatada na literatura como tóxica para humanos e animais, apresentou uma grande quantidade de alcalóides, substâncias conhecidas por suas propriedades alucinógenas, sendo extensamente estudadas em Nicotiana tabacum (Solanaceae) (Raven et al., 2001) e Cannabis sativa (Cannabaceae) (Furr \& Mahlberg, 1981). Os alcalóides de Nicotiana tabacum são produzidos nas raízes e então transportados para a folha (Raven et al., 2001). Já em Cannabis sativa, os alcalóides foram detectados apenas nos laticíferos de órgãos aéreos (Furr \& Mahlberg, 1981). Em Leguminosae, várias espécies são conhecidas pela presença de substâncias tóxicas nas raízes, como aquelas incluídas no "complexo timbó", consideradas ictiotóxicas devido à presença de rotenóides (Tozzi, 1998) e flavonóides (Garcez et al., 1988). Muitas das espécies deste complexo já são utilizadas na pecuária e na farmacologia. Como exemplos têm-se Dahlstedtia pentaphylla, conhecida como falso-timbó, cujo extrato da raiz mostrou-se eficiente como bactericida para bovinos (Pereira \& Famadas, 2004), e Glycyrrhiza glabra, cujos flavonóides das raízes são empregados como béquico, expectorante e emoliente (Oliveira et al., 1998).

A presença de compostos fenólicos, alcalóides e substâncias lipídicas e protéicas, observada em $I$. suffruticosa e I. truxillensis, não está associada a estruturas especializadas na produção e secreção de metabólitos secundários (estruturas secretoras), e sim a células não especializadas nesta função, como as parenquimáticas. Estruturas secretoras, como idioblatos e tricomas secretores, têm sido comumente observadas em outras espécies brasileiras de Indigofera (F. S. Marquiafável, dados não publicados).

A ocorrência de alcalóides é um caráter quimiotaxonômico na subfamília Papilionoideae. Há relatos de vários tipos de alcalóides quinolizidínicos, dipepiridínicos e pirrolizidínicos, muitos destes já isolados e identificados em aproximadamente 60 gêneros desta subfamília (Kinghorn \& Smolenski, 1981). Para um gênero tão especioso como Indigofera (Polhill et al., 1981), estudos fitoquímicos futuros seriam de grande contribuição para a delimitação taxonômica de espécies e para o estabelecimento de filogenias do grupo.

\section{AGRADECIMENTOS}

Agradecemos à Fundação de Amparo e Pesquisa do Estado de São Paulo pelo financiamento do trabalho (bolsa concedida à primeira autora 03/12921-1 e auxílio projeto 02/11834-5), a Vani Maria Alves Côrrea, José Augusto Maulin, Maria Dolores S. Ferreira (Laboratório de Microscopia Eletrônica do Departamento de Biologia Celular e Molecular e Bioagentes Patogênicos - FMRP/ USP) e Mario Sadaiti Ogasawara (Laboratório de Farmacobotânica - FCFRP/USP) pelo auxílio técnico.

\section{REFERÊNCIAS}

Agra MF, França PF, Barbosa-Filho JM 2007. Synopsis of the plants known as medicinal and poisonous in Northeast 
of Brazil. Rev Bras Farmacogn 17: 114-140.

Anvisa 2000. Resolução RDC 17, de 24 de fevereiro de 2000. Disponível em http://e-legis.bvs.br/leisref/public. Acesso em 10/6/2005.

Barbosa Neto JDN, Oliveira CMC, Peixoto PV, Barbosa IBP, Ávila SC, Tokarnia CH 2001. Anemia hemolítica causada por Indigofera suffruticosa em bovinos. Pesq Vet Bras 21: 18-22.

Bentham G 1859. Leguminosae L. 1. In: von Martius, C.F.; Endlicher, S. and Urban, I. (eds.). Flora Brasiliensis. V.15. Frid. Lipsiae: Fleischer. Monachii.

Bhalla NP, Dakwake RN 1978. Chemotaxonomy of Indigofera Linn. J Indian Bot Soc 57: 180-185.

Bhaskr AE, Ganga N, Arivudaimbi R, Santhanum G 1982. Antiinflammatory, analgesic activities of Indigofera aspalthoides. J Med 76: 115-116.

Bonati A 1973. Medicinal plants and industry. Boll Chim Farm 112: 796.

Bortoluzzi RLC, Garcia FCP, Carvalho-Okano RM, Tozzi AMGA 2003. Leguminosae-Papilionoideae no Parque Estadual do Rio Doce, Minas Gerais, Brasil. I: trepadeiras e subarbustos. Iheringia, Série Botânica 58: 25-60.

Brito MP 2004. Estudos farmacognósticos de Smallanthus sonchifolius (Asteraceae) e obtenção de seus extratos fluido e seco. Dissertação de Mestrado, Faculdade de Ciências Farmacêuticas de Ribeirão Preto, Universidade de São Paulo, Ribeirão Preto, SP.

Burkart A 1942. Las especies de Indigofera de la Flora Argentina. Darwiniana 4: 145-178.

Carvalho FSR, Pessoa JM, Santos HL, Eurides D 1990. Aspectos anátomo-histopatológicos da intoxicação experimental de ovinos pela Indigofera truxillensis H.B.K. Arq Bras Med Vet Zootec 42: 287-295.

Ferrante LMS, Mayer B, Vasconcelos EC, Oliveira CMR 2007. GC/FID-based authentication of Baccharis trimera: a quality control study of products commercialized in Curitiba and metropolitan region (Brazil). Rev Bras Farmacogn 17: 356-360.

Ferreira LS, Marsola FJ, Teixeira SP 2006. Anatomia dos órgãos vegetativos de Dieffenbachia picta Schott (Araceae) com ênfase na distribuição de cristais, laticíferos e grãos de amido. Rev Bras Farmacogn 16 (Suppl.): 664-670.

Fisher DB 1968. Protein staining of ribboned epon sections for light microscopy. Histochemie 16: 92-96.

Furr M, Mahlberg PG 1981. Histochemical analysis of lacticifers and glandular trichomes in Cannabis sativa. J Nat Prod 44: 153-159.

Garcez FR, Scramin S, Nascimento MC, Mors WB 1988. Prenylated flavonoids as evolutionary indicators in the genus Dahlstedtia. Phytochemistry 27: 1079-1083.

Garcez WS, Garcez FR, Honda NK, Silva AJR 1989. A nitropropanoyl-glucopyranoside from Indigofera suffruticosa. Phytochemistry 28: 1251-1252.

Jensen WA 1962. Botanical histochemistry: principles and practice. San Francisco: W. R. Freeman.

Johansen DA 1940. Plant Microtechnique. New York: McGraw-Hill Book Company Inc.

Karnovsky MJ 1965. A formaldehyde fixative of high osmalarity for use in eletron microscopy. J Cell Biol 27: 137A-138A.

Kinghorn AD, Smolenski SJ 1981. Alkaloids of Papilionoideae.
In: Polhill, R.M. and Raven P.H. (org.). Advances in Legumes Systematics. Part 2. Kew: Royal Botanic Gardens, p. 585-598.

Kissman KG, Groth D 1999. Plantas infestantes e nocivas. Tomo II, 2 ${ }^{\mathrm{a}}$ ed. São Bernardo do Campo: BASF.

Leite SP, Silva LLS, Catanho MTJA, Lima EO, Lima VLM 2003. Anti-inflammatory activity of Indigofera suffruticosa extract. Rebrasa 7: 47-52.

Lorenzi H, Abreu-Matos FJ 2002. Plantas medicinais no Brasil: Nativas e Exóticas. Nova Odessa: Instituto Plantarum.

Marques LC, Pieri C, Roman-Júnior WA, Cardoso MLC, Milaneze-Gutierre MA, Mello JCP 2007. Controle farmacognóstico das raízes de Heteropteris aphrodisiaca O. Mach. (Malpighiaceae). Rev Bras Farmacogn 17: 604-615.

Martins ER, Castro DM, Castellani DC, Dias JE 2000. Plantas medicinais. Viçosa: Editora UFV.

Moreira JLA, Tozzi AMGA 1997. Indigofera L. (Leguminosae, Papilinoideae) no estado de São Paulo, Brasil. Rev Bras Bot 20: 97-117.

O'Brien TP, McCully ME 1981. The study of plant structure. Principles and Selected Methods. Melbourne: Termarcarphi PTY Ltda.

Oliveira F, Akisue G, Akisue MK 1998. Farmacognosia. $1^{\text {a }}$ ed. São Paulo: Atheneu.

Oliveira RB, Godoy SAP, Costa FB 2003. Plantas Tóxicas: Conhecimento e prevenção de acidentes. Ribeirão Preto: Holos.

Pereira JR, Famadas KM2004. Avaliação “in vitro" da eficiência do extrato da raiz do timbó (Dahlstedtia pentaphylla) (Leguminosae, Papilionoidae, Millettieae) sobre Boophilus microplus (Canestrini, 1887) na região do Vale do Paraíba, São Paulo, Brasil. Arq Inst Biol 71: 443-450.

Polhill RM, Raven PH, Stirton CH 1981. Evolution and Systematics of the Leguminosae. In: Polhill, R.M. and Raven P.H. (org.). Advances in Legumes Systematics. Part 1. Kew: Royal Botanic Gardens, p. 1-26.

Rao JUM, Hanumaiah T, Rao BK, Rao KVJ 1984. A new flavonol glycoside from the leaves of Indigofera hirsuta Linn. J Ind Chem Soc 23: 91.

Raven PH, Evert RF, Eichhorn SE 2001. A composição molecular das células vegetais. In: Raven P.H.; Evert R. F. and Eichhorn S.E. (orgs). Biologia Vegetal. $6^{\mathrm{a}}$ ed. Rio de Janeiro: Guanabara Koogan, p. 17-39.

Ribeiro RL, Bautista PLAR, Silva AR, Sales LA, Salvadori DMF, Maia PC 1991. Toxicological and toxicogenetic effects of plants used in popular medicine and in cattle food. Mem I Oswaldo Cruz 86: 89-91.

Tokarnia CH, Dobereiner J, Peixoto PV 2000. Plantas Tóxicas do Brasil. Rio de Janeiro: Helianthus.

Tozzi AMGA 1998. A identidade do timbó-verdadeiro: Deguelia utilis (A. C. Sm.) A. M.G. Azevedo (Leguminosae - Papilionoideae). Rev Bras Biol 58: 511-516.

Vieira LS. 1992. Fitoterapia da Amazônia. Manual de plantas medicinais. A farmácia de Deus. $2^{\text {a }}$ ed. São Paulo: Agronômica Ceres.

White PS 1980. Indigofera. Ann Miss Bot Gard 67: 706-714. Williams MC 1981. Nitro compounds in Indigofera species. Agron J 73: 434-436. 